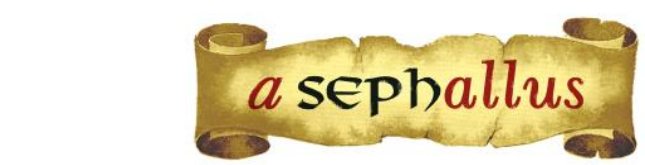

Revista aSEPHallus de Orientação Lacaniana

Núcleo Sephora de Pesquisa sobre o Moderno e o Contemporâneo

ISSN $1809-709 \mathrm{X}$

\title{
Fenômenos psicossomáticos: uma questão para a psicanálise
}

Denise Maria Lopes Dal-Cól

Doutora pela Universidade Federal do Rio de Janeiro (UFRJ). Psicanalista, Docente do Departamento de Psicologia e Psicanálise do Curso de Psicologia da Universidade Estadual de Londrina (UEL), Londrina, Paraná. Artigo baseado na tese de doutorado A escrita e o corpo em psicanálise e sua implicação nos fenômenos psicossomáticos, 2016, Programa de Pós-Graduação em Teoria Psicanalítica, UFRJ.

E-mail: denise dalcol@hotmail.com

Maria Cristina Poli

Doutora em Psicologia pela Université de Paris 13. Psicanalista, Docente do Programa de Pós-Graduação em Teoria Psicanalítica da UFRJ, Coordenadora do Mestrado Profissional em Psicanálise, Saúde e Sociedade da UVA/RJ, Pesquisadora do CNPq e jovem cientista do Estado pela FAPERJ.

E-mail: mccpoli@gmail.com

Resumo: Esse artigo aborda o percurso de uma revisão histórico-conceitual e clínica sobre os fenômenos psicossomáticos (FPSs) na psicanálise, especialmente na orientação lacaniana, elaborando uma hipótese de pesquisa. Esses fenômenos colocam-se no limite das elaborações teóricas e metodológicas da medicina e da psicanálise, impondo paradoxos em seu entendimento e tratamento. No campo psicanalítico existem divergências conceituais e em relação às formas de intervenção na clínica. Trabalha-se com a hipótese de que, se uma escrita é feita para não esquecer, o FPS é uma escrita (de gozo) no corpo que é justamente feita para não esquecer porque não foi recalcada.

Palavras-chave: clínica; psicanálise; fenômenos psicossomáticos; escrita; corpo.

\section{Phénomènes psychosomatiques: une question pour la psychanalyse}

Cet article traite du parcours d'une révision historique-conceptuelle et clinique sur les phénomènes psychosomatiques (PPs) dans la psychanalyse, en particulier dans l'orientation lacanienne, en préparant une hypothèse à cette recherche. Ces phénomènes sont placés à la frontière des elaborations teoriques et metodologiques de la médecine et de la psychanalyse, en imposant des paradoxes pour sa compréhension et son traitement. Dans le domaine de la psychanalyse, il y a quelques différences conceptuelles et quelques différences en ce qui concerne les formes d'intervention en clinique. On travaille avec l'hypothèse que, si l'écriture est faite pour ne pas oublier, le PPs est une écriture (de jouissance) sur le corps qui est faite seulement pour ne pas oublier, justement parce qu'elle n'a pas été refoulée.

Mots-clés: clinique; psychanalyse; phénomènes psychosomatiques; écriture; corps.

\section{Psychosomatic phenomena: a matter for psychoanalysis}

This article discusses the journey of a historical, conceptual and clinical review on psychosomatic phenomena in psychoanalysis, especially following the Lacanian orientation, by developing a research hypothesis. These phenomena stand on the edge of theoretical and methodological elaborations of medicine and psychoanalysis, imposing paradoxes in their understanding and treatment. In the psychoanalytic field there are conceptual differences and different forms of clinical interventions. It works with the hypothesis that, if a writing is made not to be forgotten, the psychosomatic phenomenon is a writing (of jouissance) in the body that is precisely made not to be forgotten because it was not repressed.

Keywords: clinic; psychoanalysis; psychosomatic phenomena; writing; body. 


\title{
Fenômenos psicossomáticos: uma questão para a psicanálise
}

\author{
Denise Maria Lopes Dal-Cól \& Maria Cristina Poli
}

Entre as doenças ou manifestações patológicas que se apresentam no corpo e que por vezes demandam tratamento à clínica médica ou à clínica psicanalítica destacam-se os sintomas histéricos, a angústia e as doenças psicossomáticas. Em todas elas se encontra a característica comum de manifestação corporal apresentando disfunção ou perturbação das funções dos órgãos, porém sua abordagem pela psicanálise ou pela medicina será bastante distinta.

No domínio da ciência médica, o corpo é definido em sua dimensão biológica e a doença, como existência autônoma, é autenticada por uma lesão anatomoclínica (Abreu, 1992). É nessa perspectiva que na medicina se realizam o diagnóstico e o tratamento de doenças. Por sua vez, no campo psicanalítico, o corpo é definido não no plano biológico, mas a partir de sua organização pulsional, cujo limite ultrapassa o corpo como organismo, ou seja, o órgão tomando sentido e função em referência à linguagem (Valas, 1990). Em outros termos, a noção de corpo na psicanálise depende da estrutura de linguagem, na medida em que esta produz no humano outra dimensão para além do biológico, orgânico ou fisiológico - a pulsão e sua representação no inconsciente. Nesse plano é que se dá a investigação das doenças do corpo no domínio da psicanálise.

Se na perspectiva psicanalítica o corpo é do desejo e do gozo, os quais constituem o sujeito na sua construção histórica (e podem acarretar impasses que se manifestam em doenças corporais), na perspectiva médica, essa dimensão do corpo fica excluída. Lacan (1966) chega a considerar que esta relação da medicina com o corpo é uma falha epistemossomática, uma vez que nela o corpo é considerado como um sistema homeostático, em sua pura presença animal.

Desde a fundação da psicanálise até os dias atuais, os sintomas histéricos e a angústia parecem estar bem estabelecidos, clínica e conceitualmente, ou seja, suas formas de expressão, seus mecanismos de formação e sua causa, bem como as condições de possibilidade de tratamento. São doenças que têm inscrição no campo de linguagem, sendo, por isso, legíveis a partir do inconsciente. Já as doenças psicossomáticas, embora a investigação de sua causa também tenha antigas origens, continuam sendo um campo de inúmeras incógnitas, uma vez que se colocam no limite das elaborações teóricas e metodológicas tanto da medicina quanto da psicanálise, impondo problemas e paradoxos em seu entendimento e tratamento.

Entre psicanalistas, como veremos, existem muitas divergências a respeito dessas afecções, não só conceituais, mas, sobretudo em relação às formas de intervenção possíveis na clínica. $\mathrm{Na}$ psicanálise de orientação lacaniana verifica-se que a doença psicossomática é um enigmático fenômeno clínico que, diferentemente do sintoma e da angústia, obedece apenas à alternância entre presença e ausência de lesões no corpo, nos órgãos, o que não exclui sua relação com a linguagem, porém não a coloca inteiramente nela. Nesta abordagem, uma das incógnitas que a doença psicossomática traz diz respeito à função de escrito no corpo, que Lacan (1975/1998) reconhece 
nessas afecções, sobretudo porque se trata de algo escrito que não se sabe ler, isto é, como se algo estivesse escrito no corpo, mas fosse ilegíve/ pelo inconsciente.

Neste artigo, nos propomos a situar como essa hipótese de trabalho - que ainda precisa ser demonstrada -, seu valor e função clínica, se inscrevem no amplo campo de estudos das doenças (afeç̧̃̃es ou fenômenos, a querela já inicia na denominação) psicossomáticas. Limitaremos nosso estudo nesse artigo, para fins de concisão e precisão da questão, à sua abordagem na psicanálise.

\section{Sintomas histéricos e angústia}

Se, desde Freud, sabe-se da importância das distinções diagnósticas e causais dos sintomas histéricos e da angústia para possibilitar um tratamento psicanalítico, diferenciando-os entre si e, ainda, dos quadros orgânicos, é fundamental não só relembrar, como também sublinhar seu valor na investigação freudiana: a angústia vivida no corpo, juntamente com os sintomas corporais da histeria, consistem em modalidades do fenômeno clínico que permitiram a Freud um acesso original e uma concepção inovadora do que é o corpo e do que é a mente na formulação do conceito de pulsão e de inconsciente (Dal-Cól, 2002).

Em sua investigação, Freud não atribui o lugar da causa dessas doenças nem ao corpo biológico, nem à mente consciente. O mental, no discurso freudiano, não é a consciência nem o cerebral, mas o inconsciente constituído por uma trama ideativa que conta a história dos investimentos pulsionais. Inconsciente esse que, conforme Lacan, é congruente à estrutura da linguagem. Do mesmo modo, o corpo, para além do somático ou orgânico que o constitui, é considerado na sua dimensão pulsional. Nesse sentido, a pulsão tornou-se o conceito-chave que expõe como o soma se implica ou é implicado na psique. Nos termos do autor:

[...] conceito situado na fronteira entre o mental e o somático, como o representante psíquico dos estímulos que se originam dentro do organismo e alcançam a mente, como uma medida de exigência feita à mente no sentido de trabalhar em consequência de sua ligação com o corpo. (Freud, 1915/1987, p. 142)

Se, nesses casos de sintomas e angústia, a cada tratamento, renova-se a possibilidade de acesso ao inconsciente do sujeito em questão em suas relações ao desejo e à pulsão, isto é, sua forma de satisfação ou gozo, uma vez que são legíveis, não se pode dizer o mesmo com relação à doença psicossomática, como veremos no decorrer deste trabalho.

Retomando as distinções entre sintomas histéricos e angústia no campo psicanalítico, na perspectiva clínica-descritiva, verifica-se que a angústia manifesta-se por distúrbios de determinadas funções corporais, tais como distúrbios da atividade cardíaca (palpitações, arritmia ou taquicardia) e respiratória (várias formas de dispneia nervosa, acessos semelhando a asma e similares), acessos de suor, fome devoradora, tremores, calafrios, diarreias, distúrbios esses que nem sempre vêm 
acompanhados de angústia reconhecível. Outros distúrbios corporais de angústia, como acessos de vertigem locomotora e acessos de parestesias (sensações anormais; alucinações sensoriais) raramente ocorrem sem angústia ou sensação semelhante de mal-estar (Freud, 1895/1987).

Nos sintomas histéricos, observa-se sua expressão sintomática sob a forma de dores, paralisias ou alterações de sensibilidade, inexplicáveis pelo modelo neuroanatômico. Na histeria, assim como na angústia, se uma função corporal é atingida, o organismo fica intacto. No entanto, na angústia, pode ainda produzir danos lesionais secundários.

Na perspectiva clínica-conceitual freudiana, o sintoma histérico é um símbolo que tem sua representação no inconsciente; obedece às leis de linguagem sendo estruturada por elas, juntamente com um modo de satisfação pulsional. Tem, pois, inscrição (escrita) no corpo, sendo legível a partir da consideração do inconsciente. Já a angústia não é um símbolo, não é feita de representações, embora indique representações. É um afeto especial (quantum libidinal) derivado da pulsão, seja pelo recalque primário, angústia real (Real Angst) e automática, ou pelo recalque secundário, angústia sinal. A angústia sinaliza a emergência do desejo inconsciente, assim como o "movimento pulsional" em busca de satisfação, ambos tomados pelo eu como um perigo (de dano narcísico) (DalCól, 2005).

Se Freud deixa um legado acerca dos sintomas histéricos e da angústia, não produz nenhuma pesquisa direta, ao menos nesses termos, sobre as doenças psicossomáticas. Entretanto, assim como pensamos (Dal-Cól, 2002), alguns pesquisadores como Fonseca (2007) e Nicolau (2008) consideram que dos estudos de Freud (1895/1987) sobre as neuroses atuais - neurose de angústia e neurastenia - resultaram formulações que se aproximam do que atualmente se denomina psicossomática. 0 fenômeno psicossomático (FPS) estaria próximo das neuroses atuais estudadas por Freud porque não estaria em jogo uma satisfação substitutiva de uma fantasia de conteúdo sexual como na histeria, mas a difícil elaboração psíquica da excitação somática, uma vez que essa não encontra um fiador psíquico para a excitação derivada do corpo.

Outros pesquisadores como Guir \& Valas (1989) concordam com essa observação, incluindo aí os estudos de Freud sobre as neuroses traumáticas, embora não exponham seus motivos. Uma pista para pensar essa questão é dada por Soler (2009), quando diz que as neuroses traumáticas de guerra, dos acidentes - são caracterizadas pelo esquecimento impossível das cenas traumáticas, que voltam como imagens vivas (alucinatórias), por não serem inscritas no discurso da memória inconsciente.

Apesar das aproximações referidas das afeç̧ões psicossomáticas com as neuroses de angústia e as neuroses traumáticas, elas se diferem em alguns aspectos. Com relação à primeira, entendemos que a presença de lesão histologicamente verificada é uma característica da afecção dita psicossomática que não é encontrada na maioria dos estados de angústia, a não ser como dano secundário. Em relação às neuroses traumáticas, é nossa hipótese que as afeç̧ões psicossomáticas 
podem também caracterizar um "esquecimento impossível" e, talvez, retornar como marcas, traços vivos, inscritos na carne.

Na sequência, veremos brevemente em que panorama estão inseridas as pesquisas atuais acerca das doenças psicossomáticas no campo psicanalítico. Observamos, ainda, que ordem de doenças podem ser caracterizadas como psicossomáticas, de que modo se apresentam suas manifestações e com quais elementos conceituais podemos contar atualmente na psicanálise para a sua compreensão.

\section{As afecções psicossomáticas}

Assim como os sintomas histéricos e a angústia, também o fenômeno clínico nomeado psicossomático apresenta-se sob a forma de expressão corporal, porém, diferentemente dos dois primeiros, é caracterizado por uma lesão no órgão. Algumas pesquisas em psicanálise pós-freudiana de orientação lacaniana, realizadas por Jean Guir (1992), descrevem diversas lesões psicossomáticas, tais como: manifestações alérgicas; glaucoma; fenômenos psicossomáticos cutâneos (psoríase e vitiligo); eczemas; asma, enxaquecas; gota; herpes; retocolite úlcerohemorrágica; cloasma (máscara da gravidez), peladas ou alopecias, edema de Quincke, exoftalmia da doença de Basedow; algumas doenças cancerosas, etc.. Pesquisas em outros campos teóricos metodológicos, por exemplo, em psiconeuroimunologia, consideram também afecções psicossomáticas o lúpus eritematoso, a esclerose sistêmica progressiva, o hipertireodismo, a miastenia grave, a esclerose múltipla, as síndromes de Reiter e de Sjögren e a colite ulcerativa (Ávila, 2002).

O termo "psicossomática", segundo Abreu (1992), foi criado em 1818 pelo médico clínico e psiquiatra Heinroth para expressar "a influência das paixões sexuais sobre a tuberculose, a epilepsia e o câncer", ideia que não se desenvolveu na medicina. Sendo o século 19 o século das descobertas físico-químicas e bacteriológicas, tal perspectiva encaminhou os médicos a dedicarem-se a essas doenças como existência autônoma, autenticada por uma lesão anatomoclínica, tratando-se de pesquisar uma etiologia específica e um agente patogênico (Abreu, 1992).

Desde então, as doenças psicossomáticas vêm sendo pesquisadas pela medicina a partir dessa referência anatomoclínica. Porém, dentro do campo médico causam problemas, uma vez que, conforme Guir (1992), sua etiopatogenia é imprecisa e raramente existe um tratamento específico; do ponto de vista histológico, as lesões são múltiplas, sendo algumas dessas afecções relacionadas a uma resposta imunológica.

Assim como Guir, a pesquisadora Sagna (1996) evoca o caráter orgânico da doença psicossomática pela presença invariável de lesão ou dano histológico, que, entretanto, não têm as mesmas características das lesões de causa puramente orgânica, tal como responder aos critérios exigidos para a constituição de uma doença - causa, sintoma, tratamento, prognóstico. São, assim, situadas à margem do saber médico. Dentre as características das lesões psicossomáticas 
encontram-se sintomas de gradação variável, evolução imprevisível, podendo se agravar com complicações que colocam em perigo a vida do sujeito, ou simplesmente desaparecer. O decorrer da doença se caracteriza pela presença de surtos evolutivos, fazendo da vida do paciente uma alternância entre o aparecimento e o desaparecimento da lesão (Sagna, 1996). Além dos surtos sucessivos - repetição em impulsões sucessivas -, suas manifestações podem também se mobilizar, conjugar-se, intercambiar-se, alternar-se (Lacan, 1955-1956/1988).

Abreu (1992) considera que outra forma de abordagem dessas doenças, a medicina psicossomática, irá se apropriar da concepção da psicanálise das determinações inconscientes, e entenderá que os conflitos rejeitados pelo campo da consciência explicam o modo de intervenção da psique no soma. Acrescentamos que com isso, a medicina psicossomática apoia-se na ideia da dualidade corpo/mente, demonstrando que compreende a mente como um duplo do corpo.

Se Heinroth foi o criador do termo psicossomática, coube a George Groddeck, médico contemporâneo de Freud, inaugurar a pesquisa psicossomática moderna e a possibilidade da aplicação da psicanálise à compreensão do processo do adoecer e de suas significações (Ávila, 2002). Em uma primeira carta a Freud, Groddeck apresenta um resumo do seu pensamento, indicando que ao aplicar a psicanálise aos "males orgânicos" os compreendia como expressão de um conflito simbólico, estendendo a todas as doenças a interpretação conferida aos sintomas neuróticos. Conforme Groddeck (citado por Ávila, 2002):

A psicanálise, se eu bem compreendo, trabalha no momento com a noção de neurose. Presumo, todavia, que, para você também, atrás dessa palavra se encontre a vida humana inteira. Em todo caso, assim o é para mim. $O$ id, que se mantém em misteriosa conexão com a sexualidade, o Eros, ou qualquer outro nome que se the queira dar, forma tanto o nariz como a mão do ser humano, assim como seus pensamentos e seus sentimentos. Manifesta-se tanto na pneumonia ou no câncer como na neurose obsessiva ou na histeria. E do mesmo modo que a atividade do id, aparecendo como histeria ou neurose, é objeto de tratamento psicanalítico, assim também o será a doença cardíaca ou o câncer. Em essência não existem diferenças que possam nos levar a aplicar aqui, e não lá, a psicanálise. (Groddeck citado por Ávila, 2002, p. 11)

Circunscrevendo nesse ponto as pesquisas sobre a doença psicossomática ao campo psicanalítico, veremos, a seguir, que mesmo nesse campo, posições diversas serão adotadas em relação a ela, tanto conceituais quanto na forma de tratamento, constituindo tanto um problema, quanto uma incógnita.

\section{A psicossomática na psicanálise: principais correntes}


O eixo condutor dessas elaborações será a distinção feita por Valas (1990) entre três grandes correntes dentro da pesquisa das doenças psicossomáticas na psicanálise:

1) A corrente que concebe a afecção psicossomática como detentora de um sentido, tal como o sintoma neurótico, o que significa atribuí-lo a uma causalidade psíquica (inconsciente), cujo representante inicial foi George Groddeck. Para o autor, todas as doenças orgânicas se originariam de uma fonte psíquica, mais especificamente de um desejo inconsciente, por exemplo, um câncer do colo do útero seria a expressão de um desejo de um filho. Já Franz Alexander introduz a noção de neurose vegetativa, segundo a qual haveria um efeito direto dos afetos sobre o corpo, sendo a doença uma consequência de impulsões não satisfeitas, desviadas e reprimidas (Valas, 1990). Entende-se aqui que o "desejo fundamental reprimido" durante muito tempo pode agir sobre o sistema endócrino e vegetativo e acarretar lesões corporais. Alexander fala, por exemplo, que uma pessoa que sofre de úlcera do estômago poderia padecer de uma "sede de amor", a qual remontaria à primeira infância. Outros autores afirmam ainda que existe um laço entre uma doença psicossomática e uma característica de personalidade, por exemplo, a asma atacaria pessoas com dificuldades na decisão de se casar.

Essa primeira corrente partiria do princípio de que os afetos podem ser recalcados. A energia liberada pelo recalque desses afetos acarretaria lesões no corpo. Entretanto, como sublinha Valas (1990), essa tese de que o afeto pode ser recalcado é contrária à letra do texto freudiano. Ele nota ainda que tais autores designam esse processo ocorrido na produção das doenças psicossomáticas pelo termo "conversão simbólica", tomando-o como uma novidade, o que na realidade, é a própria definição de conversão histérica.

2) A segunda corrente teórica proposta por Valas (1990) é aquela para a qual os fenômenos psicossomáticos não têm sentido. Esta é a posição da Escola de Psicossomática da Sociedade Psicanalítica de Paris, cujos representantes principais são R. Held, Marty, Fain, M'Uzan e David. Para eles, os fenômenos psicossomáticos se ligam a uma carência das atividades de representação, sendo esses situados fora-de-sentido; não obstante, traduziriam um sentido, o que seria, segundo Valas (1990), um paradoxo no seu raciocínio. Haveria lesão corporal porque a ausência de representação faz a libido e a agressividade se confundirem, transformando-se em energia pulsional indiferenciada, submetendo o corpo ao impacto direto das forças pulsionais liberadas. Essas, privadas do veículo das representações, passam diretamente ao órgão, lesionando-o, pois o "instinto" (sic) de morte destacado do "instinto" (sic) de vida continuaria um trabalho de sapa (abertura de fossos subterrâneos; buraco escavado ao pé do muro para derrubá-lo) em profundidade sobre o corpo. Assim, conforme a Escola de Paris, o tratamento não consiste em encontrar um sentido para esses sintomas, mas atribuir-Ihe um, construindo para esses pacientes uma fantasia, empregando-se, para isso, a sugestão, a explicação e até a reeducação (Valas, 1990). 
3) A terceira corrente apresentada considera que os fenômenos psicossomáticos têm sentido próximo ao da conversão histérica, mas não "totalmente". Seu expositor seria J. P. Valabrega, segundo o qual (Valas, 1990) o fantasma do doente é tomado em um sintoma que - diferente do fantasma do neurótico - está no corpo do sujeito sem que seja reconhecida por ele, como se a manifestação psicossomática fosse estranha à sua vida. Esses fantasmas se formariam num momento em que a relação simbólica com o meio não foi elaborada.

Para Valas (1990), Valabrega procurou evitar os impasses precedentes, encontrando uma saída média entre a posição que faz da manifestação orgânica a expressão simbólica de um conflito e a que a situaria fora de toda simbolização. Conforme aponta, a saída de Valabrega é estender a noção de conversão, entendendo que há uma conversão psicossomática, sem, no entanto, discernila. O tratamento proposto por Valabrega visa dar segurança ao doente tentando restituir o sentido de suas relações com o mundo.

Em sua análise crítica, Valas (1990) considera que a descrição clínica dos fenômenos psicossomáticos feita por essas correntes é, em conjunto, homogênea, e sua teoria a partir dos conceitos freudianos é confusa - todas elas admitindo a seu modo a noção de um sujeito psicossomático específico, entendido aqui como uma categoria nosográfica particular. Quanto ao tratamento, as três correntes concordam: esses doentes precisariam de uma terapêutica que buscasse reduzir a afecção pela interpretação, que vai da simples explicação à sugestão, sendo esses fenômenos qualificados de sintomas por todos, mesmo por aqueles que os situam fora de sentido.

Conforme se pode perceber, a intervenção da psicanálise neste campo de investigação não é suficiente para estabelecer um estatuto consistente da doença psicossomática, uma vez que também aí reina uma espécie de confusão e de desacordo que, no nosso entendimento, centralizase nos conceitos fundamentais da psicanálise desde Freud: desde a noção de inconsciente e pulsão e, por consequência, à conceituação de sintoma e à própria concepção de corpo. Qual seria então o alcance da psicanálise para as afecções psicossomáticas, que, com alguns indícios em Freud e de forma mais evidente a partir de Lacan, leva a crer que se trata de doenças "limites", que parecem evocar o poder do real mais do que nas neuroses? Talvez porque, nas neuroses o real se amarre com o simbólico na estrutura do sintoma e no FPS não possamos falar de sintoma. É um fenômeno, um real desgarrado do simbólico.

Paralelamente às citadas correntes de pesquisa no campo psicanalítico, Jacques Lacan abre algumas perspectivas de abordagem de compreensão da afecção psicossomática. É essa perspectiva que nos orientará na questão do modelo conceitual próprio às doenças psicossomáticas na psicanálise, especialmente a diferença entre o sintoma e o fenômeno psicossomático, no que diz respeito à exigência de satisfação pulsional e seus caminhos de derivação em que parece se circunscrever a questão da escrita.

\section{A doença psicossomática no campo lacaniano}


A pesquisa sobre a doença psicossomática no campo lacaniano se origina por iniciativa de um de seus alunos - Jean Guir -, que faz um depoimento a esse respeito, juntamente com Patrick Valas, em uma entrevista a uma revista de psicanálise do Campo Freudiano no Brasil (Guir \& Valas, 1989).

Guir trabalhou sobre os FPSs em duas versões, como ele o diz. A primeira, apoiada nas elaborações de Lacan no Seminário 11 (Lacan, 1964/1985), é a versão da holófrase ${ }^{1}$ que reduz o par significante ao $S_{1}$ (ao Um), isto é, produz uma gelificação, uma colagem do significante que, com isso, perde seu estatuto significante tornando-se um sinal (palavras impostas, gozo imposto). Segundo o autor, na clínica, a metáfora da gelificação do significante se concretiza numa holófrase, encontrada num contexto particular no discurso analítico, como nas entrevistas preliminares ou na expressão de um sonho (Guir, 1990). São essas holófrases particulares - que se situam no mesmo nível do "umbigo dos sonhos", do recalcamento originário - que incidem no corpo produzindo FPS (Guir \& Valas, 1989).

Há casos, por exemplo, em que o sujeito começa a falar a propósito de suas lesões com um estilo proverbial - certos enunciados particulares -, isto é, sentenças que o guiam na vida como se nesse ponto ele não mais estivesse em uma relação dialética com o Outro. São enunciados tais como - "aquele que não trabalha, não suja jamais as mãos" -, enquanto apresenta um eczema nas mãos (Guir \& Valas, 1989, p. 39). No caso clínico abordado por Sagna (1996, p. 61), o paciente dizia "a gente é besta", concepção da existência homogênea a seu modo de vida: ele é açougueiro que retalha e escalpela coelhos, enquanto apresenta uma séria e importante psoríase, placas que advêm em surtos.

Assim, nessa vertente da relação do FPS com a estrutura de linguagem, segundo Guir e Valas (1989), haveria uma conjuntura particular, um conjunto estrutural particular, que comporia a história da lesão psicossomática. Considera ainda que a convergência de datas particulares possa ser um determinismo de linguagem (significante) do FPS na história do sujeito. Ou seja, datas específicas (por exemplo, aniversários, nascimentos) que compõem a história do sujeito funcionariam como significantes.

A segunda versão do trabalho de J. Guir sobre o FPS se apoia na asserção de Lacan (1975/1998), na Conferência de Genebra, sobre a necessidade de abordar o FPS a partir de seu gozo específico. Essa versão trata, então, de articular ao sujeito o gozo implicado no FPS. Guir liga o FPS ao segundo tempo do fantasma "uma criança é batida", em que haveria esse gozo particular de ser batido pelo pai; um gozo de ordem masoquista, ligado ao sadismo original. Esse gozo masoquista é ao mesmo tempo imposto pelo pai, pois tem relação com a culpabilidade do gozo auto erótico (do corpo próprio) (Guir \& Valas, 1989).

Para Valas (1990), os fenômenos psicossomáticos dão testemunho do fracasso da estruturação subjetiva, uma vez que, mesmo sendo ligados a efeitos de linguagem, conforme o 
observa Lacan (1964/1985, p. 215), estão fora da dialética do significante ou das leis de linguagem. O autor considera que nos FPSs tudo se passaria como se o sujeito sentisse a imposição sobre si das significações confusas do discurso do Outro que, à força de se repetir, causariam trauma e, no lugar do compromisso sintomático (que supõe a castração no campo do Outro), inscrever-se-iam as lesões corporais dos fenômenos psicossomáticos, fazendo curto-circuito no Outro. A asma em crianças, por exemplo, poderia ser engendrada pela perturbação de uma necessidade fundamental, tal como a necessidade alimentar, pelo desejo muito exigente da mãe. Entendemos que isso corresponde à indicação de Lacan (1954-1955/1991) no Seminário 2, conforme veremos adiante, que nos FPSs o investimento da libido se faz sobre o órgão próprio - investimentos intra orgânicos, auto eróticos nos quais não se pode distinguir a fonte da pulsão de seu objeto. Para Valas (1990) essa proposição ficará como referência central a uma espécie de curto-circuito na montagem pulsional.

Valas (1990) considera ainda que a doença psicossomática não deve ser reduzida à lesão corporal apresentada pelo sujeito, mas à manifestação de um gozo no discurso que perturba pela insistência. É esse o elemento chave que distingue uma lesão psicossomática de uma lesão puramente orgânica na qual a presença do gozo não exerce este efeito durável e insistente sobre o discurso do sujeito.

Assim como Valas (1990), Miller (1990), apoiado nas elaborações de Lacan no Seminário 11, destaca que o FPS, diferentemente do sintoma analítico, não estaria inteiramente no campo da linguagem, mas sim em seu limite. Entende que, para situar esse limite, pode-se dizer que o FPS, de certo modo, contorna a estrutura de linguagem. O FPS seria um fenômeno do traumatismo, mal distinguido como evento histórico, biográfico, justamente porque não estaria transposto, metaforizado, pela estrutura de linguagem, mas pelo contrário, diretamente inscrito. Tal fenômeno não põe em questão o desejo do Outro, mas, sim, opera um contorno do Outro. $O$ autor distingue então o FPS do sintoma, especialmente o histérico, em que essa relação ao Outro lhe é constitutiva. Para este autor, no campo psicanalítico lacaniano o que é psicossomático é chamado fenômeno para distingui-lo de sintoma que possui uma definição muito precisa: o sintoma tem estrutura de linguagem que supõe substituição (metáfora) e está aberta ao deslocamento retroativo.

O autor indica, tal como Lacan (1964/1985) o afirma, que o FPS estaria inscrito numa série em que se incluem a debilidade infantil e a psicose (paranoia), pois tais casos:

[...] se situam num nível em que o sujeito cessa de ser representado, e em que, de certo modo, falta a descontinuidade. São casos onde não estamos em presença de uma articulação significante, porém onde está em função a presença ou ausência de um significante unário, de um significante privilegiado - um $\mathrm{S}_{1}$, portanto, de certa forma, absoluto. (Miller, 1990, pp. 89-90) 
Miller (1990, p. 90) observa a necessidade de qualificar esse $S_{1}$ que está em questão nos FPSs, uma vez que esse conceito seria o pivô em torno do qual giramos para a compreensão de tais fenômenos. Para pensar a questão do $S_{1}$ - significante único e não articulado -, o autor propõe uma série de conceitos de Lacan, entre os quais o traço unário. O traço unário, podemos acrescentar, mantém relação com a escrita dos FPSs, uma vez que, se o $S_{1}$ porta o traço de gozo que se repete na série dos significantes $\left(S_{2}, S_{3}, S_{4} \ldots\right)$, nos FPSs o traço de gozo não se repetiria ("embutiria") em um significante retirado do Outro.

Assim como Miller, também Sagna (1996) sublinha a diferença entre sintoma analítico e fenômeno psicossomático: o FPS não é como o sintoma, mensagem cifrada, retorno do recalcado que pode ser objeto de uma queixa no discurso do paciente. O sintoma analítico, estruturado pelas leis de linguagem denominadas condensação e deslocamento por Freud e metáfora e metonímia por Lacan, tem a substituição como seu modo de formação necessário. Sua natureza é mudar de sentido para o sujeito, pela colocação em palavras, assim como pela interpretação, existindo, porém, no próprio sintoma uma satisfação que coloca obstáculo à sua mobilização.

Já a lesão psicossomática não obedece às leis da linguagem, não responde a uma estrutura metafórica, senão a uma alternância de presença e ausência (Sagna, 1996). Para Sagna (1996) o FPS se desenvolve ao lado da estrutura do sujeito, da qual ele não é o produto, mas também não é absolutamente sem ligação com ela. A autora acentua que há na doença psicossomática a dimensão de algo que se mostra - phainomenein, do grego phanómenon: aquilo que aparece.

\section{As referências de Jacques Lacan}

Lacan aborda a questão dos fenômenos psicossomáticos no decorrer de seu ensino no Seminário 2: o eu na teoria de Freud e na técnica da psicanálise (1954-1955/1991); no Seminário 3: as psicoses (1955-1956/1988); no Seminário 11: os quatros conceitos fundamentais da psicanálise (1964/1985); e na Conferência de Genebra sobre o sintoma (1975/1998). Nessas ocasiões faz alguns apontamentos relacionados com sua diferença dos sintomas, bem como uma interrogação sobre sua pertinência estrutural e o gozo implicado neles. Deixa preciosas observações clínicas e apontamentos conceituais das quais se valem, além desta autora, diversos autores, conforme vimos, para produzir suas pesquisas. Visamos, sobretudo, nesta nossa pesquisa, desdobrar e investigar as afirmações de Lacan (1975, p. 14) sobre o FPS como algo da ordem de uma escrita no corpo que não sabemos ler. Apresentaremos, assim, o panorama das elaborações de Lacan sobre o FPS desde o Seminário 2 até a Conferência de Genebra sobre o sintoma onde situa o FPS no registro da escrita.

No Seminário, livro 2, Lacan (1954-1955/1991, p. 127) situa, diríamos resumidamente, os fenômenos psicossomáticos como "reações psicossomáticas dos órgãos". Estas reações estão fora do âmbito das construções neuróticas, uma vez que nelas não se trata de uma relação ao objeto, mas de algo que está no limite das elaborações conceituais da psicanálise, algo "em que se pensa sempre, de que se fala por vezes, e que propriamente falando não podemos apreender e que, no 
entanto está aí". A partir da consideração do ternário estrutural - Simbólico, Imaginário e Real Lacan considera que as relações psicossomáticas estão no nível do Real.

No ponto de elaboração que Lacan (1954-1955/1991, p. 128) está nesta época, o real é definido como "o que é sem fissura"; é neste nível, segundo o autor, que a distinção entre exterioridade e interioridade não tem nenhum sentido. Sublinha que o que ensina desde as formulações de Freud acerca das pulsões é que "este real, para apreendê-lo, não temos outros meios - em todos os planos, e não somente do conhecimento - a não ser por intermédio do simbólico".

Lacan (1954-1955/1991, p. 129) diferencia essa premissa, da concepção da biologia, cuja "petição de princípio" consiste em considerar um Umwelt [fora] e um Innenwelt [dentro], o que implica na hipótese da adaptação preestabelecida, na noção de relações do ser vivo que se refletem com seu meio. Para ele, na psicanálise, a distinção entre os aparelhos que têm relação com o real e os aparelhos não relacionais se efetua entre o que está incluído na relação narcísica e o que não está; isto é, na juntura do imaginário e do real. Depreende-se que é nessa juntura que se situa o fenômeno psicossomático, mesmo nível do autoerotismo, "estado hipotético de auto encerramento que na teoria freudiana supõe-se ser o estado do sujeito logo no início", no nível do próprio corpo.

No Seminário 3 (Lacan, 1955-1956/1988, p. 361), a propósito dos sintomas (sic) hipocondríacos em um caso de psicose, Lacan salienta que no fundo da relação psicótica pode-se ver alguma coisa como um fenômeno psicossomático, sendo estruturados de forma diferente das neuroses, em que há "uma impressão ou inscrição direta de uma característica, e mesmo, em certos casos, de um conflito, no que se pode chamar o quadro que apresenta o sujeito enquanto ser corpóreo". O autor apresenta como exemplo um caso em que uma erupção dermatológica (diferentemente tanto de uma lesão puramente orgânica quanto de uma construção neurótica) pode se mobilizar em função de um aniversário. A expressão corporal se deu de modo direto, sem que uma interpretação pudesse marcar a correspondência com alguma coisa do passado do sujeito (Lacan, 1955-1956/1988).

No Seminário 11, no contexto das elaborações acerca dos quatro conceitos fundamentais da psicanálise, Lacan (1964/1985) articula como a linguagem aparelha o corpo. Elabora a constituição da estrutura pulsional e o nascimento do sujeito no campo do Outro. Nesse contexto, aborda o que chama de efeito psicossomático, diferenciando-o de uma produção subjetiva posto que não envolveria uma representação.

Lacan (1964/1985, pp. 193-194) irá deduzir uma topologia para apresentar a constituição do sujeito, na qual localiza dois campos - do sujeito e do Outro: "O Outro é o lugar em que se situa a cadeia do significante que comanda tudo que vai poder se presentificar do sujeito" - campo do vivo, onde o sujeito tem que aparecer e no qual se manifesta a pulsão. A pulsão, parcial, não representa a função de reprodução no psiquismo, só situa equivalentes atividade/passividade, não representando o ser macho ou ser fêmea. Essa divisão torna necessário que as vias do que se pode fazer como homem ou mulher se coloque no campo do Outro, pelo roteiro do Édipo. Dessa forma, 
a sexualidade se deduz de outra coisa que não da sexualidade mesma - a sexualidade se instaura no psiquismo pela via da falta.

Duas faltas se recobrem: a falta que advém do "defeito central" na qual gira a dialética do sujeito, isto é, a relação de dependência do sujeito do significante do Outro; a falta real "que é o que o vivo perde, de sua parte de vivo ao se reproduzir pela via sexuada" (Lacan, 1964/1985, p. 193), falta essa que é retomada pela falta significante. Da estrutura do significante na qual se funda a função do corte, se estabelece a função topológica de borda que articula a relação do sujeito ao Outro. O sujeito vê a si mesmo aparecer no campo do Outro e de lá retorna num processo circular dissimétrico, uma vez que retorna o significante (e não o objeto de satisfação esperado), "reduzindo o sujeito em instância a não ser mais do que um significante, petrificando-o pelo mesmo movimento com que o chama a funcionar, a falar, como sujeito", ponto de partida do inconsciente - o fechamento (Lacan, 1964/1985, p. 197). Lacan (1964/1985, p. 198) chama esse movimento fading do sujeito ou afânise, movimento radical e letal de desaparecimento. É nesse sentido que na constituição do sujeito no campo do Outro, em seu nascimento, "a característica do sujeito do inconsciente é de estar, sob o significante que desenvolve suas redes, suas cadeias e sua história, num lugar indeterminado".

Retomando sumariamente as duas operações de constituição do sujeito no campo do Outro: a primeira operação, a alienação, articula-se num ve/no qual se inscreve a dupla significante mínima - "não há algo...sem outra coisa" (não há Fort, sem Da, em referência ao jogo observado por Freud em Além do princípio do prazer). De acordo com Lacan (1964/1985, p. 206), se Freud observa que o recalcamento cai sobre algo que é da ordem da representação denominado por ele Vorstellungsrepräsentanz, ele, Lacan (1964/1985, pp. 205-207), a identifica em seu ensino como o acasalamento dessa primeira dupla significante, nos mecanismos originais da alienação. Isso lhe permite "conceber que o sujeito aparece primeiro no Outro, no que o primeiro significante, o significante unário, surge no campo do Outro, e no que ele representa o sujeito, para um outro significante" (Lacan, 1964/1985, p. 205), outro significante que tem por efeito a afânise do sujeito. Resulta na divisão do sujeito que, quando "aparece em algum lugar como sentido, em outro lugar ele se manifesta como fading, como desaparecimento" (Lacan, 1964/1985, p. 205). Há então, "questão de vida e de morte entre o significante unário e o sujeito enquanto significante binário, causa de seu desaparecimento. O Vorstellungsrepräsentanz é o significante binário" (Lacan, 1964/1985, p. 207). Esse significante se constitui como o ponto central do recalque, o ponto de atração de todos os outros recalques.

Pela separação, o sujeito encontra o ponto de retorno do ve/ da alienação no intervalo entre esses dois significantes; intervalo onde mora o desejo que se oferece como balizamento ao sujeito no discurso do Outro - no caso, o primeiro Outro, a mãe. Isto porque, seu desejo está para aquém ou além no que ela diz e faz surgir como sentido, e, na medida em que seu desejo é desconhecido, nesse ponto de falta é que se constitui o desejo do sujeito (Lacan, 1964/1985, p. 297). Assim, por 
esse processo de engano, de torção, o sujeito reencontra o ponto inicial que é sua falta, sua afânise (1964/1985, p. 207). Em uma análise, o sujeito tem que se libertar do efeito afanísico do significante binário, função da liberdade (Lacan, 1964/1985, p. 208). Em suma, sublinha Lacan (1964/1985, p. 209): "Não há sujeito sem, em alguma parte, afânise do sujeito, e é nessa alienação, nessa divisão fundamental, que se institui a dialética do sujeito".

No contexto desses aportes sobre as operações de constituição do sujeito, Lacan desenvolve algumas importantes ideias acerca dos efeitos psicossomáticos. Nos fenômenos psicossomáticos reside uma questão sobre a função do Outro, esse lugar do Vorstellungsrepräsentanz ou significante binário. Isto porque, nesses efeitos psicossomáticos "a indução significante, no nível do sujeito, se passou de maneira que não põe em jogo a afânise do sujeito" (1964/1985, p. 215). Isto é, não produziu sua falta.

Lacan (1964/1985, p. 215) considera que o fenômeno psicossomático não é um significante, mas mesmo assim, pensa que ele só é concebível considerando a indução significante. Seria isso que o faz dizer que a psicossomática é 'em aparência', muito afastada do domínio da psicanálise. De alguma forma o significante participa dos efeitos psicossomáticos. A psicossomática não pode ser concebida como advinda de um duplo psíquico para tudo que se passa no somático, sublinha Lacan (1964/1985, p. 215), uma vez que uma necessidade pode estar interessada na função do desejo: "se falamos de psicossomática é na medida em que deve aí intervir o desejo", o elo do desejo fica conservado mesmo que não seja possível identificar a afânise do sujeito.

Na experiência do reflexo condicionado de Pavlov realizada em um cão, Lacan extrai certas consequências para pensar sobre os efeitos psicossomáticos na vertente do significante e do desejo. Ele observa que o reflexo condicionado só é possível porque o exercício de uma função biológica não é unificante, mas desmontável, isto é, mais de um órgão interfere nessa função. Portanto, quando o experimentador faz secretar seu cão à vista de um pedaço de carne, recorta, a partir daí, a região da secreção salivar e mostra que esta é articulável a algo - no caso, o sinete - que funciona como significante uma vez que é feito pelo experimentador. $\mathrm{E}$, sendo assim, está aí o Outro. Mas no nível do animal não se trata de uma representação, mas de percepção. No animal, os significantes (que são os nossos porque os escalonamos em percepção), traduzem uma espécie de equivalência (1964/1985, pp. 214-216).

Se a alienação se produz - o significante é o que representa o sujeito para outro significante -, resulta que no nível do outro significante o sujeito se desvanece, por isso o Vorstellungsrepräsentanz é o $S_{2}$ da dupla. É a essência da linguagem, a qual "não reduz a função do significante à nomeação, isto é, uma etiqueta colocada sobre uma coisa" (Lacan, 1964/1985, p. 223). Por isso, é possível situar que na experiência do reflexo condicionado não é a associação de um signo a uma coisa. Associa-se um significante que faz o corte - corte do desejo - na organização orgânica da necessidade, e com isso, são produzidos ciclos de necessidades interrompidas. Mas, se 
a experiência pode provocar desordens, problemas no cão, não sendo ele um ser falante, "ele não é chamado a pôr em questão o desejo do experimentador" (1964/1985, p. 223-224).

Enfim, para Lacan (1964/1985, pp. 224-225), o interesse essencial da experiência de Pavlov é permitir situar que se deve conceber o efeito psicossomático como a ausência de intervalo entre $S_{1}$ e $S_{2}$, quando a primeira dupla se solidifica, se holofraseia. Observa essa condição em uma série de casos: na criança débil que a mãe reduz a ser suporte de seu desejo num termo obscuro; na psicose, na qual a solidez, o apanhar a cadeia primitiva em massa proíbe a abertura dialética, isso se manifestando no fenômeno da crença - na paranoia, ausência de um termo da crença em que se designa a divisão do sujeito. Entretanto, nessa série, não se trata de o sujeito ocupar o mesmo lugar (Lacan, 1964/1985, p. 225).

Para Lacan, portanto, a psicossomática é um efeito, fenômeno que não tem relação com as estruturas clínicas neurose, psicose, perversão, sendo possível produzirem-se esses fenômenos psicossomáticos em qualquer dessas estruturas. Trata-se, nesse Seminário 11, de uma abordagem do FPS pela vertente do significante e do desejo, na qual procura dar conta da simbolização primordial. O que fica fora dela, que Lacan (1972-1973) nomeia posteriormente de gozo Outro, estaria implicado na linguagem, mas seria uma ordem de escrita que não passa pela dialética significante, lugar do FPS.

Deste modo, parece que no FPS, algo da pulsão não se representou no inconsciente para entrar na cadeia significante. Ficou livre, pulsão não ligada, porém fez uma marca 'thanática' no corpo. O significante faz corte na organização orgânica da necessidade, provocando desordens, uma vez que não se associa à cadeia significante; conserva um elo ao desejo, mas não possibilita a separação - o pôr em questão o desejo do Outro pela palavra, bem como a inscrição do movimento, da demanda pulsional. Assim, mesmo dependendo da estruturação subjetiva - do significante - os FPSs parecem ser fenômenos "à parte" ou ao lado da estrutura, por isso ilegível.

Foi somente em 1975, na Conferência de Genebra sobre o Sintoma, no contexto das discussões com o público, que Lacan (1975/1998) observou que os FPSs são "da ordem da escrita" - como se algo estivesse escrito no corpo como um enigma perante o qual nada entendemos, isto é, enigma que não sabemos ler, diferentemente do sintoma que é passível de leitura:

Certamente que se trata de um domínio mais que inexplorado. Finalmente, é de todo modo, algo da ordem do escrito. Em muitos casos, não sabemos lê-lo. Teria de dizer aqui alguma coisa que introduzisse a noção de escrito. Tudo se passa como se algo estivesse escrito no corpo, alguma coisa que nos é dado como um enigma. Não é de modo algum surpreendente que tenhamos como analistas essa sensação [de não haver alcançado o registro do simbólico]. (Lacan, 1975/1998, p. 14) 
Se Lacan (1975/1998, p. 14) afirma que o FPS é uma escrita no corpo que não sabemos ler, ele não explora este tema: "[...] teria de dizer aqui alguma coisa que introduzisse a noção de escrito". Assim, nos perguntamos que escrita e que corpo seriam esses dos FPSs? Porque não sabemos lêla? A pesquisa que estamos desenvolvendo marca essa dimensão da escrita e do corpo do FPS e tem por finalidade desdobrá-la e investigá-la no seu percurso.

\section{Considerações Finais}

Dissemos que a pesquisa em psicanálise acerca do corpo desde sua fundação por Freud se insere no contexto do tratamento de doenças, tais como a histeria (sintomas) e a angústia (afeto), uma vez que essas se manifestavam em expressões corporais, em padecimentos corporais. As doenças ditas psicossomáticas também se apresentam clinicamente no corpo, mas têm um lugar de exceção no estatuto psicanalítico freudiano e lacaniano de sintoma, assim como da angústia. Seu principal diferencial clínico é a presença de lesões que também têm lugar de exceção no campo médico, pois, embora perfeitamente orgânicas, uma vez que há sempre um dano histológico, suas características (sintomas de gradação variável, evolução imprevisível) não correspondem às das lesões de causa puramente orgânica. Elas podem se agravar ou simplesmente desaparecer, e costumam se expressar em surtos sucessivos cujas manifestações podem se alternar, intercambiarse, conjugar-se. É, portanto, um problema também para a medicina.

Conforme vimos, no campo lacaniano, as doenças psicossomáticas são consideradas fenômenos, uma vez que não obedecem às leis de linguagem como o sintoma; não respondem a uma estrutura metafórica, senão a uma alternância de presença e ausência. Apesar disso, conforme Lacan, a lesão pode ser induzida por um significante ou conjunto de significantes, estando, portanto, ligada à linguagem, porém não de modo dialetizável, mas holofraseado, solidificado. Nesses fenômenos reconhece-se um gozo - "gozo específico" -, diferenciado do gozo do sintoma: uma "reação de órgão". É uma escrita no corpo "que não se sabe ler", isto é, escrita que parece ilegível, intraduzível. Os FPSs constituem, por isso, um problema conceitual e clínico para a psicanálise.

No estágio atual dessa questão, situaríamos assim o que resta a avançar: qual é a função do escrito e o estatuto da leitura em psicanálise? O que é ler em psicanálise? Em outras palavras, para que serve escrever? Se uma escrita é feita para não esquecer - é um registro mnemônico -, o FPS seria uma escrita no corpo para não esquecer? Não pode esquecer porque não foi recalcada.

Mas por que esse registro tem que estar no real do corpo na forma de lesão, sendo assim algo que parece intraduzível? Se nos sintomas as fixações (libidinais) contam uma história que se registra no inconsciente como uma "fixão" - uma fiç̧ão que fixa e esquece porque já entrou nesta história -, nos FPSs ocorre uma fixação do gozo - "fixão" que não se torna ficção porque não articulada à cadeia ou série significante não pode contar sua história.

Os fenômenos psicossomáticos parecem mostrar no corpo uma escrita apenas como marcas registradas que não se inserem numa história, numa escrita da história libidinal capaz de ser contada, 
reconstruída, como nos sintomas neuróticos. Em outros termos, nos FPSs, há um registro, uma escrita de gozo que causa efeitos, mas não se inscreve na dimensão significante como cadeia articulada $\left(\mathrm{S}_{2}\right)$, sendo por isso "um modo espeć́fico de gozo" (Lacan, 1975/1998).

Assim, nosso trabalho visa investigar o FPS como algo que aponta para um limite da linguagem em suas relações com o corpo, e que justamente coloca em questão os limites de possibilidade do método psicanalítico. Importa investigar também o FPS como apontando para um modo específico de gozo, independente da estrutura psíquica. Há algo que ocorre aí, nesses fenômenos, que não interfere na estruturação, mas fixa no corpo e produz efeitos - algo da pulsão é registrado no corpo como uma escrita que não entra na dialética da palavra.

Conforme mostramos em nosso breve panorama sobre os FPS, existem muitas divergências dentro do campo psicanalítico, não só conceituais, mas, sobretudo, em relação às formas de intervenção possíveis na clínica. Alguns autores como Groddeck e Alexander consideram viável uma interpretação dos FPS, como decifração de um sentido latente; outros, como Marty, M'Uzan e David, admitem que há uma ausência de simbolização em jogo, o que exigiria que se mobilize a construção de um sentido para o doente; outros, como Valabrega, consideram ainda desejável encontrar uma terceira via. Sem ainda incluir Lacan nessa série, acreditamos que esse mapeamento sumário das diferenças entre as escolas já nos indica o quanto o campo dos FPS é, de fato, um território repleto de incógnitas.

Abordando mais estritamente as contribuições de Lacan sobre o tema, pode-se observar que os FPS representam um desafio tanto teórico quanto clínico. Um desafio teórico, na medida em que os FPS permitem abordar uma questão fundamental para a psicanálise que diz respeito ao modo de inscrição da linguagem sobre o corpo. O FPS sinaliza para algo no corpo que está fora, mas fora de que? Não está totalmente no registro do biológico, porém tampouco se inscreve no inconsciente como discurso recalcado $\left(\mathrm{S}_{2}\right)$.

Um desafio clínico, na medida em que se mantém viva a discussão sobre quais as intervenções possíveis nos casos de FPS. Evitando-se tanto a interpretação quanto a atribuição de um sentido tal como fazem as outras correntes, é preciso saber se é possível e como é possível, amarrar, engatar o FPS na articulação significante, encaminhando o tratamento analítico. Isto é, se um trabalho analítico pode permitir a leitura desse gozo específico marcado no corpo.

\section{Nota:}

${ }^{1}$ Termo que denota "enunciado composto de uma única palavra, que equivale a uma frase completa" (Ferreira, 2009, p. 1052).

\section{Referências Bibliográficas}

Abreu, C. R. (1992). Apresentação. In: J. Guir. Psicossomática na clínica lacaniana (pp. 9-24). Rio de Janeiro: Jorge Zahar. 
Ávila, L. A. (2002). Doenças do corpo e doenças da alma: investigação psicossomática psicanalítica. São Paulo: Escuta.

Clastres, G. (2012). Retornos: o sujeito: cadernos 3. Curitiba: Escola da Coisa Freudiana.

Dal-Cól, D. M. L. (2005). O legado freudiano: a angústia na clínica psicanalítica e na cultura contemporânea. Doxa - Revista Paulista de Psicologia e Educação, 9(1), 47-88. São Paulo.

Dal-Cól, D. M. L. (2002). Um estudo sobre a teoria da angústia na obra de Sigmund Freud-caminhos de construção e de descoberta. (Dissertação de Mestrado). Retirado da base de dados da Universidade Estadual Paulista.

Ferreira, A. B. H. (2009). Novo dicionário da língua portuguesa. Rio de Janeiro: Nova fronteira.

Fonseca, M. C. B. (2007). Do trauma ao fenômeno psicossomático (FPS) - lidar com o sem-sentido? Ágora, 10(2), 229-244. Rio de Janeiro: UFRJ.

Freud, S. (1987). Sobre os fundamentos para destacar da neurastenia uma síndrome específica denominada 'neurose de angústia'. In J. Salomão (Trad.) Edição standard brasileira das obras completas de Sigmund Freud (Vol. III, pp. 91-117). Rio de Janeiro: Imago (Texto original publicado em 1895).

Freud, S. (1987). Os instintos e suas vicissitudes. In J. Salomão (Trad.) Edição standard brasileira das obras completas de Sigmund Freud (Vol. XIV, pp. 115-145). Rio de Janeiro: Imago (Texto original publicado em 1915).

Guir, J. (1990). Fenômenos psicossomáticos e função paterna. In: Wartel, R. Merlet, A., Laurent, E., Blancard, M-H, Josselin, F., Guir, J., Kaltenbeck, F., Valas, P., \& Miller, J-A. Psicossomática e psicanálise (pp. 47-57). Rio de Janeiro: Jorge Zahar.

Guir, J. (1992). A psicossomática na clínica lacaniana. Rio de Janeiro: Jorge Zahar.

Guir, J. \& Valas, P. (1989). Entrevista. Correio do Simpósio, 3(5), 34-41.

Infopédia (2013). Enciclopédia e dicionário. Porto: Porto Editora. Recuperado de http://www.infopedia.pt/lingua-portuguesa/hol\%C3\%B3frase.

Lacan, J. (1998). Conferência de Genebra sobre o sintoma. Opção Lacaniana: Revista Brasileira de Psicanálise, (23), 6-16. São Paulo: Eólia (Conferência proferida em 1975).

Lacan, J. (1991). O seminário, livro 2: o eu na teoria de Freud e na técnica da psicanálise. Rio de Janeiro: Zahar (Texto original publicado em 1954-1955).

Lacan, J. (1988). O seminário, livro 3: as psicoses. Rio de Janeiro: Zahar (Texto original publicado em 1955-1956).

Lacan, J. (1985). O seminário, livro 11: os quatro conceitos fundamentais da psicanálise. Rio de Janeiro: Zahar (Texto original publicado em 1964).

Lacan, J. (1985). O seminário, livro 20: mais, ainda. Rio de Janeiro: Zahar (Texto original publicado em 1972-1973). 
Lacan, J. (1966). Psicanálise e medicina. Intervenção em mesa redonda, realizada no Colégio de Medicina, em 16 de fevereiro de 1966 na Salpêtriere. (Tradução de Léo Cardon para uso interno do Serviço de Psicopatologia do H.C da UFPR).

Miller, J.-A. (1990). Algumas reflexões sobre o fenômeno psicossomático. In: Wartel, R. Merlet, A., Laurent, E., Blancard, M-H, Josselin, F., Guir, J., Kaltenbeck, F. Valas, P., \& Miller J-A. Psicossomática e psicanálise (pp. 87-97). Rio de Janeiro: Jorge Zahar.

Nicolau, R. F. (2008). A psicossomática e a escrita do real. Revista Mal-Estar e Subjetividade, 8(4), 959-990.

Sagna, C. D. (1996). Lesões sensíveis à palavra. Opção Lacaniana: Revista Brasileira de Psicanálise, (17), 60-62. São Paulo: Eólia.

Soler, C. (2009). De un trauma al Otro. Seminário Internacional en La Escuela de Psicoanálisis de los Foros Del Campo Lacaniano. Medellín: Asociación Foro Del Campo lacaniano de Medellín.

Valas, P. (1990) Horizontes da psicossomática. In: Wartel, R., Merlet, A., Laurent, E., Blancard, MH., Josselin, F., Guir, J., Kaltenbeck, F., Valas, P., \& Miller, J-A. Psicossomática e psicanálise (pp. 69-86). Rio de Janeiro: Jorge Zahar.

Wartel, R. (1990). O que esperem de nós os médicos? In: Wartel, R., Merlet, A., Laurent, E., Blancard, M-H., Josselin, F., Guir, J., Kaltenbeck, F., Valas, P., \& Miller J-A. Psicossomática e psicanálise (pp. 17-24). Rio de Janeiro: Jorge Zahar.

Citacão/Citation: Dal-Cól, D. M. L. \& Poli, M. C. (mai. a out. 2016). Fenômenos psicossomáticos: uma questão para a psicanálise. Revista aSEPHallus de Orientação Lacaniana, 11(22), 122-140. Disponível em www.isepol.com/asephallus. doi: 10.17852/1809-709x.2019v11n22p122-140.

Editor do artigo: Tania Coelho dos Santos.

Recebido/Received: 03/09/2016 / 09/03/2016.

Aceito/Accepted: 02/10/2016 / 10/02/2016.

Copyright: (C) 2013 Associação Núcleo Sephora de Pesquisa sobre o moderno e o contemporâneo. Este é um artigo de livre acesso, que permite uso irrestrito, distribuição e reprodução em qualquer meio, desde que o autor e a fonte sejam citados/This is an open-access article, which permites unrestricted use, distribution, and reproduction in any medium, provided the author and source are credited. 